\title{
RUPTURA DE LA DORMICIÓN Y EXIGENCIAS DE LUZ PARA LA GERMINACIÓN DE SEMILLAS DE Juglans nigra
}

\author{
Flores, P. ${ }^{1} ;$ Poggi, D. ${ }^{1}$; Garcia, S. ${ }^{1} ;$ Catraro, M. $^{1}$ \& Gariglio, n. ${ }^{2}$
}

\begin{abstract}
RESUMEN
Se evaluaron métodos para superar la dormición y determinar las necesidades de luz en la germinación de Juglans nigra. Para superar la latencia y dureza del endocarpio se realizó Estratificación en caliente (T1), Inmersión en ácido giberélico (T2) y Estratificación en frío-húmedo (T3). Para la necesidad de luz se evaluó alternancia de oscuridad/luz y oscuridad permanente. Se analizó el Porcentaje Germinación (\% de G), Índice Velocidad de Germinación (IVG), Tiempo Medio Germinación Máxima (TMG), \% Plántulas Normales, \% Semillas sin germinar, Peso Seco Medio de plántulas (PSM) y el Índice de Germinación Relativo a la luz (GRL). En T1 no hubo germinación y en T2 irrelevante. T3 produjo diferencias altamente significativas en todas las variables analizadas, siendo el período de 4 meses de estratificación el mejor para romper la dormición. Al no ser la luz un factor determinante en la germinación, esta especie se clasificaría como fotoblástica neutra.
\end{abstract}

Palabras clave: Juglans nigra, ruptura dormición, estratificación, exigencia luz

\begin{abstract}
Dormancy breakup and need for light in black walnut (Juglans nigra) germination.

The aims of this work were to evaluate methods to overcome the dormancy of Juglans nigra seeds, and to determine their light requirements for germination. To overcome dormancy and soften the endocarp, seeds were subjected to treatments of warm stratification (T1), gibberellic acid immersion (T2) and cold-moist stratification (T3). Light requirements for germination were evaluated
\end{abstract}

1.- Cátedra de Cultivos Intensivos. Facultad de Ciencias Agrarias (UNR). CC 14 (S2125ZAA) Zavalla, provincia de Santa Fe. Email: pflores@unr.edu.ar

2.- Cátedra de Cultivos Intensivos. Facultad de Ciencias Agrarias (UNL).

Manuscriterecibido el 16 de mayo de 2017-y aceptado para su publicación el 29 de agosto de 2017. 
though alternating light/dark and continuous darkness conditions. Germination percentage $(\% \mathrm{G})$, germination speed index (GSI), mean germination time (MGT), \% normal seedlings, \% non germinated seeds, mean dry weight of seedlings, and light-relative germination index were evaluated. No germination occurred in $\mathrm{T} 1$, and in $\mathrm{T} 2$ it was irrelevant. $\mathrm{T} 3$ presented significant differences in all the variables studied; stratification for 4 months was the best to overcome dormancy. As light is not a determining factor in germination, this species is classified as neutral photoblastic.

Key words:Juglans nigra, overcome dormancy, stratification, light requirements.

\section{INTRODUCCIÓN}

Los nogales se utilizan con un doble propósito, tanto para la producción de madera para carpintería fina como por sus frutos secos. La madera del nogal europeo (Juglans regia L.) y del nogal negro americano ( Juglans nigra L.) son consideradas las más importantes y valiosas en el mundo $(13,57)$. La madera de Juglans nigra L., denominado "el nogal negro del este", es utilizada en mueblería, ebanistería, instrumentos musicales y armería. Los frutos alcanzan altos precios y tienen la ventaja de almacenarse fácilmente $(24,37,47,51)$. Por esta razón el nogal se posiciona como una especie de gran relevancia económica, con un elevado nivel industrial y tecnológico, como se demuestra en el centro de Agroforestación de la Universidad de Missouri (25, 44, 49, 53). La Hammons Products Company (26) es el procesador y proveedor más importante en el mundo de nueces de nogal negro para alimentos y usos industriales (43). En Francia, Bulgaria y Alemania, J. nigra es utilizado para la obtención de madera y como portainjerto de J. regia $(35,49)$. En España se inició en 1993 un programa de investigación y entre sus objetivos se encuentra el uso de cruzamientos controlados entre Juglans regia x Juglans nigra para la obtención de híbridos para madera adapta- dos al clima mediterráneo (1). En Argentina el principal uso del Juglans nigra es como pie de injerto del nogal europeo (Juglans regia), debido a que ofrece tolerancia al mal de la tinta (Phytopthora cinnamonii), nemátodes, Armillaria, y agalla de cuello (27). Además, induce precocidad a la variedad o copa injertada (33). En Argentina, hacia mediados de los años 90, comenzó un proceso de reconversión en el sector nogalero promovido por el INTA y los gobiernos provinciales. Los cambios tecnológicos más importantes fueron el aumento de la densidad de plantación y el reemplazo de los nogales criollos provenientes de semilla por plantas injertadas con variedades de alto valor comercial $(6,45)$. Ante estos hechos, disponer de plantas injertadas con variedades de carga lateral y de excelente calidad de nuez es primordial dentro del conjunto del paquete tecnológico (28). El proceso de obtener nuevas plantas injertadas demanda la disponibilidad de una importante cantidad de portainjertos, entre los que se encuentran Juglans nigra (37). Para obtener pies o portainjertos de $J$. nigra se siembran a campo sus semillas y cuando las plántulas alcanzan el diámetro adecuado para recibir la púa se realiza el injerto $(18,48)$.

Las semillas de Juglans nigra presentan dormición o latencia $(8,41,46)$, lo que representa una estrategia evolutiva de 